\title{
Vasectomy and risk of prostate cancer: population based matched cohort study
}

\author{
Madhur Nayan,, Robert J Hamilton, ${ }^{1}$ Erin M Macdonald, ${ }^{2}$ Qing Li, ${ }^{2}$ Muhammad M Mamdani,,,3 \\ Craig C Earle, ${ }^{2,4}$ Girish S Kulkarni,, ${ }^{1,2}$ Keith A Jarvi, ${ }^{5}$ David N Juurlink2,6 for the Canadian Drug Safety \\ and Effectiveness Research Network (CDSERN)
}

${ }^{1}$ Division of Urology,

Departments of Surgery and

Surgical Oncology, Princess

Margaret Cancer Centre,

University Health Network and

the University of Toronto, 610

University Ave 3-130, Toronto,

ON, M5G 2M9, Canada

Institute for Clinical Evaluative

Sciences, Toronto, ON, Canada

${ }^{3}$ Li Ka Shing Knowledge

Institute, St Michael's Hospital,

Toronto, ON, Canada

${ }^{4}$ Ontario Institute for Cancer

Research, Toronto, ON, Canada

${ }^{5}$ Division of Urology,

Department of Surgery, Mount

Sinai Hospital, University of

Toronto, Toronto, ON, Canada;

Faculty of Medicine, Institute of

Medical Science, University of

Toronto, Toronto, ON, Canada:

Lunenfeld Tannenbaum

Research Institute, Mount Sinai

Hospital, Toronto, ON, Canada

${ }^{6}$ Department of Internal

Medicine, Sunnybrook Health

Sciences Centre, University of

Toronto, Toronto, ON, Canada

Correspondence to: M Nayan

madhur.nayan@mail.utoronto.ca

Additional material is published

online only. To view please visit

the journal online.

Cite this as: $B M J$ 2016;355:i5546 http://dx.doi.org/10.1136/bmj.i5546

Accepted: 05 October 2016

\section{ABSTRACT}

OBJECTIVE

To determine the association between vasectomy and prostate cancer, adjusting for measures of health seeking behaviour.

DESIGN

Population based matched cohort study.

SETTING

Multiple validated healthcare databases in Ontario, Canada, 1994-2012.

\section{PARTICIPANTS}

326607 men aged 20 to 65 who had undergone vasectomy were identified through physician billing codes and matched 1:1 on age (within two years), year of cohort entry, comorbidity score, and geographical region to men who did not undergo a vasectomy.

\section{MAIN OUTCOMES MEASURES}

The primary outcome was incident prostate cancer. Secondary outcomes were prostate cancer related grade, stage, and mortality.

RESULTS

3462 incident cases of prostate cancer were identified after a median follow-up of 10.9 years: 1843 (53.2\%) in the vasectomy group and 1619 (46.8\%) in the nonvasectomy group. In unadjusted analysis, vasectomy was associated with a slightly increased risk of incident prostate cancer (hazard ratio 1.13, 95\% confidence interval 1.05 to 1.20). After adjustment for measures of health seeking behaviour, however, no association remained (adjusted hazard ratio 1.02, 95\% confidence interval 0.95 to 1.09). Moreover, no association was found between vasectomy and high grade prostate cancer (adjusted odds ratio 1.05, 95\% confidence interval 0.67 to 1.66 ), advanced stage prostate cancer

\section{WHAT IS ALREADY KNOWN ON THIS TOPIC}

Studies evaluating the association between vasectomy and prostate cancer have provided conflicting results

These studies have generally been limited by sample size and are prone to selection, recall, and detection biases

Given the frequency of vasectomy, even a small increased risk of prostate cancer would constitute a major public health problem

\section{WHAT THIS STUDY ADDS}

In this large population based study using validated healthcare databases, vasectomy does not seem to be independently associated with risk of prostate cancer

These findings have important implications for patients, clinicians, guidelines, policy makers, and family planning support groups, and support the use of vasectomy as a safe method of contraception in men

(adjusted odds ratio 1.04, 0.81 to 1.34), or mortality (adjusted hazard ratio 1.06, 0.60 to 1.85).

\section{CONCLUSION}

The findings do not support an independent association between vasectomy and prostate cancer.

\section{Introduction}

Vasectomy is a minor outpatient procedure with few short term complications. ${ }^{12}$ It is effective in most men and one of the most reliable and cost effective long term methods of contraception. ${ }^{34}$ An estimated 33 million women worldwide rely on their partner's vasectomy for contraception. ${ }^{5}$

Several studies have explored the possible association between vasectomy and prostate cancer, with conflicting results. ${ }^{6-30}$ Potential biological mechanisms supporting an association between vasectomy and incident prostate cancer include increases in androgen levels, which are hypothesised to increase the risk of prostate cancer, ${ }^{31}$ and impaired secretory function of the prostate, which might prolong exposure of the prostate to carcinogenic factors. ${ }^{11}$ Although some studies have shown an increase in serum dihydrotestosterone and testosterone after vasectomy, ${ }^{32-34}$ others have found no statistically significant change in androgen levels. ${ }^{35} 36$ Similarly, findings on the association between frequency of ejaculation and risk of prostate cancer are conflicting . ${ }^{3738}$ Thus the possible biological relation, if any, between vasectomy and prostate cancer remains unclear.

Many of the studies that found an association between vasectomy and prostate cancer were limited by sample size and the potential for selection, recall, and detection biases. Given the frequency of vasectomy, even a small increased risk of prostate cancer would constitute a major public health problem. We examined the association between vasectomy and prostate cancer in a large population based cohort, adjusting for health seeking behaviours that might have biased other studies examining this association.

\section{Methods}

\section{Setting and data sources}

We conducted a population based matched cohort study of residents in Ontario, Canada. With a population of about 14 million in 2016,39 Ontario is Canada's most populous province, and residents have universal access to physician services and hospital care. We used the Ontario health insurance plan database to identify physician claims for vasectomy. The Ontario Cancer Registry ${ }^{40}$ was used to identify patients with incident prostate 
cancer (international classification of diseases, ninth and 10th revisions (ICD-9: 185 and ICD-10: C61, respectively), characteristics of their tumour, and date and cause of death, where applicable. It is a validated, population based tumour registry maintained by Cancer Care Ontario and is estimated to be more than 95\% complete. ${ }^{4041}$ We obtained data on admissions to hospitals from the Canadian Institute for health information discharge abstract database, ${ }^{42}$ national ambulatory care reporting system, and same day surgery database, which contain detailed clinical information on admissions to hospitals and emergency departments and outpatient surgical procedures in Ontario. We obtained basic personal data from the registered persons database, a registry of all Ontario residents eligible for health insurance. These databases were linked in an anonymous fashion using encrypted health card numbers, and are routinely used to study the long term consequences of medical care. ${ }^{43-45}$ Details of the databases used and their validity have been described elsewhere. ${ }^{46}$

\section{Study participants}

We identified all men aged 20 to 65 who underwent a vasectomy between 1 April 1994 and 31 December 2012. We excluded those with a diagnosis of prostate cancer before vasectomy, those who underwent a vasovasostomy (vasectomy reversal) at any time before the censoring date, and those who underwent other procedures on the same day that were inconsistent with receipt of a vasectomy for the purpose of contraception-for example, vasectomy performed on the same day as prostatectomy or vesiculectomy (removal of seminal vesicles). The date of vasectomy served as the index date.

For each man who underwent vasectomy, we selected one man who did not, matching on age (within two years), comorbidity score (defined using the Johns Hopkins adjusted clinical groups case mix system), ${ }^{47}$ geographical area (defined by the first three digits of the postal code), and index date. The Johns Hopkins adjusted clinical case mix system was designed to predict healthcare use and considers the duration, severity, and intensity of service use related to both inpatient and outpatient claims, details of which have been provided elsewhere. ${ }^{48}$ To assign a score to each patient for this study, we used data from Ontario health insurance plan, the Canadian Institute for Health Information, and the national ambulatory care reporting system. We randomly assigned an index date within one year of the vasectomy date of the corresponding matched participant to account for temporal changes in prostate cancer screening and diagnosis over time. Because men not undergoing a vasectomy might be infertile, and infertility might be related to risk of prostate cancer, ${ }^{49}$ we also excluded those with a diagnosis of infertility from the cohort of non-vasectomised men.

\section{Outcome assessment}

The primary outcome was incident prostate cancer, defined as the first recorded date of prostate cancer diagnosis in the Ontario Cancer Registry. Secondary outcomes included prostate cancer related grade, stage, and mortal- ity. We categorised prostate cancer grade as low (Gleason score 2-6), intermediate (Gleason score 7), or high (Gleason score 8-10), and prostate cancer stage as either localised (stage T1-2) or advanced (stage T3+, $\mathrm{N}+$, or M+).

We followed participants until their date of last contact with health services, death, or the end of the study period, whichever occurred first. For the analysis of mortality, we followed patients until 31 December 2012, the last date for which cancer specific mortality data were available. For all other outcomes, we followed patients until 31 March 2014.

\section{Covariates}

To deal with the possibility of healthy user bias, we obtained data on the number of admissions to hospitals and the number of visits to general practitioners, specialists, urologists, and emergency departments. For each of these, we identified the number of interactions in the year preceding the index date and between the index date and end of follow-up. To account for survival bias, whereby those who survive longer are likely to have a higher number of interactions with healthcare services, we standardised interactions with healthcare services to duration of follow-up by dividing the number of interactions by follow-up time.

To adjust for potential detection bias, we obtained data on the number of colonoscopies, faecal occult blood tests, and cholesterol tests. We chose these tests as they are insured under the universal healthcare system in Ontario and therefore the data were available within the databases used for this study, whereas testing for prostate specific antigen is not. We assumed that patients undergoing these prevention tests would also be likely to undergo testing for prostate specific antigen. Indeed, the association between prostate and colorectal cancer screening has been shown among men in Alberta, another province in Canada with universal healthcare. ${ }^{50}$ We similarly divided these tests into subcategories according to whether they occurred before or after the index date.

We also collected data on socioeconomic status to control for potential confounding, as such status relates to receipt of both vasectomy and cancer screening. ${ }^{5152}$ Finally, an association between sexually transmitted infections and risk of prostate cancer has been reported ${ }^{53}$; although results of testing for sexually transmitted infections are not available in administrative data, we also evaluated the number of these tests performed during the study period.

\section{Statistical analysis}

For each outcome we evaluated the standardised difference according to vasectomy or non-vasectomy group. We adjusted models based on covariates that were considered to be meaningfully different between the groups (standardised difference $>0.10$ ). As the numbers of prostate cancer specific deaths were limited, a decision was made a priori to evaluate differences between groups on age at diagnosis of prostate cancer, rural status, fifth of income, and comorbidity score only.

We obtained cumulative probability estimates for incident prostate cancer using the Kaplan-Meier method. To 
estimate the association between vasectomy and risk of incident prostate cancer and mortality, we conducted time-to-event analyses using population averaged Cox proportional hazard regression. For prostate cancer grade and stage, we used logistic regression models.

We performed a tracer analysis by examining the outcome of incident non-Hodgkin's lymphoma, in a fashion identical to the analysis of incident prostate cancer. As there is no reason to anticipate an association between vasectomy and non-Hodgkin's lymphoma, we reasoned that a positive association in this analysis would suggest that any observed association between vasectomy and risk of prostate cancer might reflect residual confounding.

All statistical analyses were performed using SAS (version 9.3; SAS Institute, Cary, NC). We considered a two sided P value of 0.05 to be statistically significant.

\section{Sensitivity analysis}

To further evaluate the potential for confounding on the association between vasectomy and risk of prostate cancer, we performed three additional analyses in which we included only income fifth, interactions with health services before index date, or interactions with health services after index date. The last two models only included variables found to be meaningfully different between the groups (standardised difference $>0.10$ ).

\section{Patient involvement}

No patients were involved in setting the research question or the outcome measures, nor were they involved in developing plans for design or implementation of the study. No patients were asked to advise on interpretation or writing up of results. No plans have been made to disseminate the results of the research to study participants; however, results will be disseminated to the relevant patient community.

\section{Results}

Over the 18 year study period, 395836 men underwent vasectomy. Of these, 326607 (82.5\%) were matched to an equal number of men who did not undergo vasectomy. Unmatched cases tended to be younger and have higher comorbidity scores than matched cases. Table 1 shows the characteristics of the cohort. The median follow-up was 10.9 years (interquartile range 6.3-15.4).

\section{Incident prostate cancer}

Overall, 3462 incident cases of prostate cancer were identified: 1843 (53.2\%) in the vasectomy group and

\begin{tabular}{|c|c|c|c|}
\hline Characteristics & $\begin{array}{l}\text { Vasectomy } \\
\text { group }(n=326607)\end{array}$ & $\begin{array}{l}\text { Non-vasectomy } \\
\text { group }(n=326607)\end{array}$ & $\begin{array}{l}\text { Standardised } \\
\text { difference }\end{array}$ \\
\hline \multicolumn{4}{|l|}{ Patients } \\
\hline Age at index date & $37.3(6.15)$ & $37.3(6.24)$ & - \\
\hline Comorbidity score (No (\%)): & & & - \\
\hline $0-4$ & $191967(58.8)$ & $191967(58.8)$ & \\
\hline $5-9$ & 126974 (38.9) & 126974 (38.9) & \\
\hline $10-14$ & $7611(2.3)$ & $7611(2.3)$ & \\
\hline $15-19$ & $55(0.0)$ & $55(0.0)$ & \\
\hline Rural (No (\%)) & $47398(14.5)$ & $48291(14.8)$ & - \\
\hline Income fifth (No (\%)): & & & 0.15 \\
\hline 1 (lowest) & $40772(12.5)$ & $55500(17.0)$ & \\
\hline 2 & $56209(17.2)$ & $61775(18.9)$ & \\
\hline 3 & $69943(21.4)$ & $68555(21.0)$ & \\
\hline 4 & $80908(24.8)$ & $74270(22.7)$ & \\
\hline 5 (highest) & $78775(24.1)$ & $66507(20.4)$ & \\
\hline \multicolumn{4}{|c|}{ Health service used in year before index date } \\
\hline Visits to general practitioners & $2.91(3.11)$ & $2.87(4.28)$ & 0.01 \\
\hline Visits to specialists & $1.23(2.32)$ & $0.93(3.08)$ & 0.11 \\
\hline Visits to urologists & $0.54(0.59)$ & $0.05(0.37)$ & 1.00 \\
\hline Admissions to hospitals & $0.02(0.14)$ & $0.03(0.21)$ & 0.08 \\
\hline Visits to emergency departments & $0.17(0.56)$ & $0.24(0.73)$ & 0.11 \\
\hline Colonoscopies & $0.01(0.11)$ & $0.01(0.11)$ & 0.01 \\
\hline Faecal occult blood tests & $0.01(0.13)$ & $0.01(0.11)$ & 0.03 \\
\hline Sexually transmitted infection tests & $0.01(0.16)$ & $0.01(0.16)$ & 0.03 \\
\hline Cholesterol tests & $0.29(0.55)$ & $0.25(0.57)$ & 0.06 \\
\hline \multicolumn{4}{|c|}{ Health service used between index date and end of follow-up (per year) } \\
\hline Visits to general practitioners & $2.34(2.62)$ & $2.86(4.07)$ & 0.15 \\
\hline Visits to specialists & $0.96(1.92)$ & $1.10(2.45)$ & 0.06 \\
\hline Visits to urologists & $0.08(0.28)$ & $0.06(0.41)$ & 0.06 \\
\hline Admissions to hospitals & $0.03(0.25)$ & $0.04(0.36)$ & 0.04 \\
\hline Visits to emergency departments & $0.29(0.49)$ & $0.35(0.94)$ & 0.08 \\
\hline Colonoscopies & $0.02(0.06)$ & $0.02(0.06)$ & 0.05 \\
\hline Faecal occult blood tests & $0.03(0.08)$ & $0.03(0.08)$ & 0.0 \\
\hline Sexually transmitted infection tests & $0.01(0.05)$ & $0.01(0.09)$ & 0.04 \\
\hline Cholesterol tests & $0.30(0.36)$ & $0.33(0.42)$ & 0.09 \\
\hline
\end{tabular}




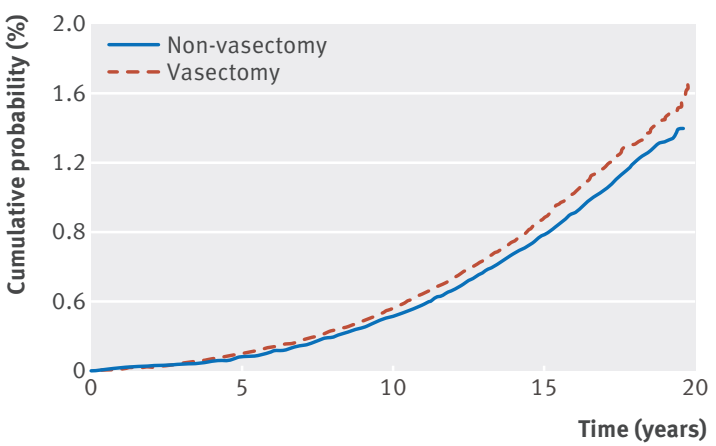

Fig 1 Cumulative probability of incident prostate cancer by vasectomy status

$1619(46.8 \%)$ in the non-vasectomy group. Figure 1 shows the cumulative probability of incident prostate cancer, stratified by vasectomy status. In the unadjusted analysis, vasectomy was associated with a modest but statistically significant increased risk of incident prostate cancer (hazard ratio 1.13, 95\% confidence interval 1.05 to 1.20 ). Variables found to be meaningfully different between the groups and included in the multivariable model were income fifth; visits to specialists, urologists, and emergency departments in the year before the index date; and visits to general practitioners between the index date and end of follow-up. After adjustment for these variables, the association between vasectomy and incident prostate cancer was no longer discernible (table 2, adjusted hazard ratio 1.02, 95\% confidence interval 0.95 to 1.09 ).

Sensitivity analyses were conducted excluding men aged less than 50 and less than 60 at their last follow-up. No association was found between vasectomy and incident prostate cancer after restricting analyses to men with follow-up at least to age 50 (adjusted hazard ratio $1.06,0.98$ to 1.15 ) or at least to age 60 (1.06, 0.91 to 1.23$)$.

\begin{tabular}{|c|c|c|}
\hline \multirow[b]{2}{*}{ Variables } & \multicolumn{2}{|l|}{ Hazard ratio $(95 \% \mathrm{Cl})$} \\
\hline & Unadjusted & Adjusted* \\
\hline No vasectomy & 1.0 (reference) & 1.0 (reference) \\
\hline Vasectomy & $1.13(1.05$ to 1.20$)$ & $1.02(0.95$ to 1.09$)$ \\
\hline \multicolumn{3}{|l|}{ Patient characteristics } \\
\hline Age at index date & 1.19 (1.18 to 1.19$)$ & - \\
\hline \multicolumn{3}{|l|}{ Comorbidity score: } \\
\hline $0-4$ & 1.0 (reference) & - \\
\hline $5-9$ & 1.51 (1.41 to 1.62$)$ & - \\
\hline $10-14$ & $2.36(1.99$ to 2.80$)$ & - \\
\hline $15-19$ & $0.001(0.001$ to 0.002$)$ & - \\
\hline \multicolumn{3}{|l|}{ Rural status: } \\
\hline Not rural & 1.0 (reference) & - \\
\hline Rural & 0.75 (0.68 to 0.83$)$ & - \\
\hline \multicolumn{3}{|l|}{ Income fifth: } \\
\hline 1 (lowest) & $0.53(0.47$ to 0.59$)$ & $0.52(0.47$ to 0.59$)$ \\
\hline 2 & 0.55 (0.50 to 0.61$)$ & 0.55 (0.49 to 0.61$)$ \\
\hline 3 & $0.62(0.56$ to 0.68$)$ & $0.62(0.56$ to 0.68$)$ \\
\hline 4 & 0.69 (0.64 to 0.76$)$ & $0.70(0.64$ to 0.77$)$ \\
\hline 5 (highest) & 1.0 (reference) & 1.0 (reference) \\
\hline \multicolumn{3}{|c|}{ Health service used in year before index date } \\
\hline Visits to general practitioners & $1.02(1.02$ to 1.03$)$ & - \\
\hline Visits to specialists & $1.02(1.02$ to 1.02$)$ & $1.02(1.01$ to 1.02$)$ \\
\hline Visits to urologists & $1.23(1.19$ to 1.28$)$ & $1.20(1.15$ to 1.24$)$ \\
\hline Admissions to hospitals & 0.89 (0.73 to 1.09$)$ & - \\
\hline Visits to emergency departments & 0.92 (0.84 to 0.99$)$ & $0.91(0.84$ to 0.99$)$ \\
\hline Colonoscopies & $2.29(1.92$ to 2.72$)$ & - \\
\hline Faecal occult blood tests & $2.10(1.78$ to 2.47$)$ & - \\
\hline Sexually transmitted infection tests & 1.00 (0.81 to 1.22$)$ & - \\
\hline Cholesterol tests & $1.48(1.43$ to 1.53$)$ & - \\
\hline \multicolumn{3}{|c|}{ Health service used between index date and end of follow-up } \\
\hline Visits to general practitioners & $1.04(1.04$ to 1.05$)$ & 1.05 (1.04 to 1.05$)$ \\
\hline Visits to specialists & $1.04(1.03$ to 1.04$)$ & - \\
\hline Visits to urologists & $1.31(1.25$ to 1.37$)$ & - \\
\hline Admissions to hospitals & $1.14(1.10$ to 1.18$)$ & - \\
\hline Visits to emergency departments & $0.63(0.55$ to 0.73$)$ & - \\
\hline Colonoscopies & 21.6 (11.3 to 41.0$)$ & - \\
\hline Faecal occult blood tests & 18.9 (14.2 to 25.1$)$ & - \\
\hline Sexually transmitted infection tests & $1.18(0.78$ to 1.77$)$ & - \\
\hline Cholesterol tests & $2.07(1.84$ to 2.32$)$ & - \\
\hline
\end{tabular}




\section{Prostate cancer grade and stage}

Cancer grade was available for 1364 (39.4\%) men with a diagnosis of prostate cancer: low grade in 540 (39.6\%), intermediate in 704 (51.6\%), and high in 120 (8.8\%) (see supplementary table $\mathrm{S} 1$ ). Compared with low grade prostate cancer, vasectomy was not associated with an increased risk of intermediate or high grade cancer in any analyses (table 3).

Cancer stage was available for 1790 (51.7\%) men with a diagnosis of prostate cancer: the cancer was localised in $1408(78.7 \%)$ and advanced at the time of diagnosis in $382(21.3 \%)$ (see supplementary table S2). Vasectomy was not associated with advanced stage at diagnosis in any analyses (table 3).

\section{Prostate cancer specific mortality}

Overall, 50 patients died from prostate cancer (see supplementary table S3). Vasectomy was not associated with prostate cancer specific mortality (table 3 ).

\section{Incident non-Hodgkin's lymphoma}

In the tracer analysis, we identified 1100 cases of incident non-Hodgkin's lymphoma: 533 (48.4\%) in the vasectomy group and $567(51.6 \%)$ in the non-vasectomy group. Vasectomy was not statistically significantly associated with incident non-Hodgkin's lymphoma (table 3).

\section{Sensitivity analysis}

The association between vasectomy and risk of prostate cancer was no longer evident when including interactions with health services before index date (see supplementary table S4).

\section{Discussion}

In this population based study spanning nearly 20 years, we observed no statistically significant association between vasectomy and prostate cancer related risk, grade, stage, or mortality. Our findings have important implications for patients, clinicians, guidelines, policy makers, and family planning support groups.
Previous studies of the association between vasectomy and prostate cancer have produced conflicting results. ${ }^{67}$ Most of these studies included fewer than 100 men with prostate cancer among those undergoing vasectomy and had limited follow-up. Furthermore, concerns have been raised about bias, unmeasured confounding, and chance in relation to the small increased risk found by others. ${ }^{25} 54$ Recently published meta-analyses of these studies found that vasectomy was not associated with risk of prostate cancer, ${ }^{67}$ and guidelines from the American Urological Association in 2012 recommended that clinicians do not need to routinely discuss prostate cancer during preoperative counselling of men considering vasectomy. ${ }^{55}$

A large prospective cohort study published in 2014, however, found that history of vasectomy was associated with a $10 \%$ increased risk of prostate cancer overall and a roughly $20 \%$ increased risk of high grade and lethal disease. ${ }^{30}$ This study received much media attention, ${ }^{56}$ might have caused anxiety among men who were planning or had already undergone a vasectomy, and even prompted a formal response from the American Urological Association. ${ }^{57}$ The study relied on data from the Health Professionals Follow-up Study, and the history of vasectomy was obtained through questionnaires and might therefore have been prone to selection and recall bias. Additional concerns raised by the American Urological Association included inconsistencies with previous reports on the same cohort of men, and residual confounding. ${ }^{57}$ After considering all the evidence to date, the association reaffirmed its 2012 guideline recommendations against routine discussion of prostate cancer during preoperative counselling of men considering vasectomy. ${ }^{57}$ Our results strengthen the current evidence and support these recommendations.

Inappropriately decreasing the use of vasectomy as a form of contraception because of concerns related to prostate cancer would be a disservice to both men and women. Compared with its female counterpart, tubal ligation, vasectomy is more cost effective, with average healthcare

\begin{tabular}{|c|c|c|c|c|}
\hline \multirow[b]{2}{*}{ Outcomes } & \multirow[b]{2}{*}{ Vasectomy group } & \multirow{2}{*}{$\begin{array}{l}\text { Non-vasectomy } \\
\text { group }\end{array}$} & \multicolumn{2}{|c|}{$\begin{array}{l}\text { Hazard ratio or odds ratio } \\
\text { (vasectomy } v \text { non-vasectomy) }\end{array}$} \\
\hline & & & Unadjusted & Adjusted \\
\hline \multicolumn{5}{|l|}{ Prostate cancer grade $(n=1364)$ : } \\
\hline High & $60(8.2)$ & $60(9.5)$ & 0.82 (0.56 to 1.22$)$ & 1.05 (0.67 to 1.66$)$ \\
\hline \multicolumn{5}{|l|}{ Prostate cancer stage $(n=1790)$ : } \\
\hline Localised & $747(78.7)$ & $661(78.6)$ & 1.0 (reference) & 1.0 (reference) $\dagger$ \\
\hline Advanced & $202(21.3)$ & $180(21.4)$ & $0.99(0.79$ to 1.24$)$ & $1.04(0.81$ to 1.34$)$ \\
\hline Cancer specific mortality & $26(0.01)$ & $24(0.01)$ & 1.01 (0.58 to 1.75) & 1.06 (0.60 to 1.85$) \neq$ \\
\hline
\end{tabular}


costs about one third of those for tubal ligation. ${ }^{58}$ Furthermore, compared with vasectomy, tubal ligation is 20 times more likely to have associated major complications, such as haemorrhage, infection, ectopic pregnancy, and injury to adjacent organs. ${ }^{58}$ Although procedure related mortality is rare, tubal ligation is about 12 times more likely to be associated with death compared with vasectomy. ${ }^{58}$ These differences are particularly important in developing countries, where risks associated with sterilisation procedures might be even greater.

\section{Strengths and limitations of this study}

Our study has several strengths. Firstly, we used a population based approach and therefore included men of all ethnicities, socioeconomic status, and with comorbidities, thereby minimising selection bias. Furthermore, because healthcare is publically administered in Ontario, all patients had universal access to healthcare services and cancer related screening. Secondly, we relied on validated, comprehensive databases, ${ }^{40-42}$ whereas most studies on this topic have relied on interviews and questionnaires. Thirdly, we were able to minimise detection bias by controlling for various kinds of interactions with healthcare services throughout the study period. Indeed, our sensitivity analysis suggests that the unadjusted analysis showing a positive association between vasectomy and risk of prostate cancer might have been driven by interactions with health services in the year before the index date. This suggests that those undergoing a vasectomy are more likely to undergo screening for prostate cancer before undergoing the procedure itself, as has been shown previously. ${ }^{26}$ Accordingly, this baseline screening might have led to risk adjusted monitoring of patients in the vasectomy group, resulting in increased detection of prostate cancer. Finally, the results of our prespecified tracer analysis evaluating incident non-Hodgkin's lymphoma, a cancer unrelated to the urinary tract or androgen levels and where no association with vasectomy would be expected, further support our findings.

Some limitations of our study merit emphasis. Firstly, although administrative data provide the advantage of studying large populations, these databases are not designed for clinical research, and some degree of outcome misclassification is likely. The databases used in this study, however, have been independently validated for cancer related outcomes. ${ }^{4041}$ Secondly, we were unable to account for possible differences in testing for prostate specific antigen between groups; our results, however, suggest that the use of surrogate cancer screening tests might have accounted for this, as shown by the strong associations between colorectal cancer screening tests and incident prostate cancer. Thirdly, data on prostate cancer grade and stage were incomplete. Fourthly, certain risk factors for prostate cancer, such as family history, ethnicity, dietary factors, use of $5-\alpha$ reductase inhibitors, and ejaculatory frequency cannot be obtained through administrative data. However, there is no reason to anticipate that these would be differentially distributed across groups. Finally, longer follow-up would have permitted ascertainment of more cases of prostate cancer. This limita- tion applies to both the vasectomy group and the non-vasectomy group and we attempted to mitigate this limitation by performing sensitivity analyses of those with follow-up at least to age 50 and 60, and found similar associations to those of our primary analysis. Despite these limitations, our study is the largest to date to evaluate the association between vasectomy and prostate cancer and found no statistically significant association between vasectomy and prostate cancer related risk, grade, stage, or mortality.

\section{Conclusion}

The findings of this study show that vasectomy does not seem to be independently associated with prostate cancer. These results support the use of vasectomy as a safe method of contraception in men.

Contributors: MN, RJH, EMM, QL, MMM, CCE, GSK, KAJ, and DNJ conceived and designed the study. QL acquired the data. MN, RJH, EMM, QL, MMM, CCE, GSK, KAJ, and DNJ analysed and interpreted the data. MN drafted the manuscript. MN, RIH, EMM, QL, MMM, CCE, GSK, $\mathrm{KAJ}$, and DNJ revised the manuscript for important intellectual content MN and QL carried out the statistical analysis, had full access to all of the data in the study, and act as guarantors for the integrity of the data and the accuracy of the data analysis.

Funding: This study was supported in part by a grant from the Canadian Drug Safety and Effectiveness Research Network, and by the Institute for Clinical Evaluative Sciences, a non-profit research institute sponsored by the Ontario Ministry of Health and Long-Term Care. DNJ is supported by the Eaton scholar award, Department of Medicine, University of Toronto. The opinions, results, and conclusions reported in this paper are those of the authors and are independent of the funding sources. No endorsement by the Institute for Clinical Evaluative Sciences or the Ontario Ministry of Health and Long-Term Care is intended or should be inferred. Parts of this material are based on data and information compiled and provided by Canadian Institute for Health Information. The analyses, conclusions, opinions, and statements expressed herein, however, are those of the authors, and not necessarily those of the Canadian Institute for Health Information. Competing interests: All authors have completed the ICMIE uniform disclosure form at www.icmje.org/coi_disclosure.pdf and declare: no support from any organisation for the submitted work; no financial relationships with any organisations that might have an interest in the submitted work in the previous three years; no other relationships or activities that could appear to have influenced the submitted work.

Ethical approval: This study was approved by the research ethics board of Sunnybrook Health Sciences Centre, Toronto, Ontario.

Data sharing: No additional data available.

Transparency: The lead authors (MN and QL) affirm that the manuscript is an honest, accurate, and transparent account of the study being reported; that no important aspects of the study have been omitted; and that any discrepancies from the study as planned (and, if relevant, registered) have been explained.

This is an Open Access article distributed in accordance with the Creative Commons Attribution Non Commercial (CC BY-NC 3.0) license, which permits others to distribute, remix, adapt, build upon this work non-commercially, and license their derivative works on different terms, provided the original work is properly cited and the use is noncommercial. See: http://creativecommons.org/licenses/by-nc/3.0/. Farley TM, Meirik O, Mehta S, Waites GM. The safety of vasectomy:
recent concerns. Bull World Health Organ 1993;71:413-9.
Jacobstein R, Pile J. Vasectomy: safe, convenient, effective-and
underutilized. Global Health Technical Briefs. 2005.
Trussell J, Lalla AM, Doan QV, Reyes E, Pinto L, Gricar J. Cost
effectiveness of contraceptives in the United States. Contraception
2009;79:5-14. doi:10.1016/j.contraception.2008.08.003.
Jamieson DJ, Costello C, Trussell J, Hillis SD, Marchbanks PA, Peterson
HB. US Collaborative Review of Sterilization Working Group. The risk of pregnancy after vasectomy. Obstet Gynecol 2004;103:848-50. doi:10.1097/01.AOG.0000123246.11511.e4.

5 Pile JM, Barone MA. Demographics of vasectomy--USA and international. Urol Clin North Am 2009;36:295-305. doi:10.1016/j. ucl.2009.05.006.

6 Shang Y, Han G, Li J, et al. Vasectomy and prostate cancer risk: a metaanalysis of cohort studies. Sci Rep 2015;5:9920. doi:10.1038/srep09920. 
7 Liu LH, Kang R, He J, et al. Vasectomy and risk of prostate cancer: a systematic review and meta-analysis of cohort studies. Andrology 2015:3:643-9. doi:10.1111/andr.12040.

8 Lynge E. Prostate cancer is not increased in men with vasectomy in denmark. J Urol 2002;168:488-90. doi:10.1016/S0022-5347(05)64664-2.

9 Goldacre MJ, Wotton CJ, Seagroatt V, Yeates D. Cancer and cardiovascular disease after vasectomy: an epidemiological database study. Fertil Steril 2005;84:1438-43. doi:10.1016/j.fertnstert.2005.04.052.

10 Cox B, Sneyd MJ, Paul C, Delahunt B, Skegg DC. Vasectomy and risk of prostate cancer. JAMA 2002;287:3110-5. doi:10.1001/jama.287.23.3110.

11 Giovannucci E, Ascherio A, Rimm EB, Colditz GA, Stampfer MJ, Willett WC. A prospective cohort study of vasectomy and prostate cancer in US men. JAMA 1993;269:873-7. doi:10.1001/ jama.1993.03500070053028.

12 Giovannucci E, Tosteson TD, Speizer FE, Ascherio A, Vessey MP, Colditz GA. A retrospective cohort study of vasectomy and prostate cancer in US men. JAMA 1993;269:878-82. doi:10.1001/ jama.1993.03500070058029.

13 Platz EA, Yeole BB, Cho E, Jussawalla DJ, Giovannucci E, Ascherio A Vasectomy and prostate cancer: a case-control study in India. Int J Epidemiol 1997;26:933-8. doi:10.1093/ije/26.5.933.

14 Rohrmann S, Paltoo DN, Platz EA, Hoffman SC, Comstock GW, Helzlsouer KJ. Association of vasectomy and prostate cancer among men in a Maryland cohort. Cancer Causes Control 2005;16:1189-94. doi:10.1007/s10552-005-0304-8.

15 Schwingl PJ, Meirik O, Kapp N, Farley TM. HRP Multicenter Study of Prostate Cancer and Vasectomy. Prostate cancer and vasectomy: a hospitalbased case-control study in China, Nepal and the Republic of Korea. Contraception 2009;79:363-8. doi:10.1016/j.contraception.2008.11.015.

16 Rosenberg L, Palmer JR, Zauber AG, et al. The relation of vasectomy to the risk of cancer. Am J Epidemiol 1994;140:431-8.

17 Lesko SM, Louik C, Vezina R, Rosenberg L, Shapiro S. Vasectomy and prostate cancer. J Urol 1999;161:1848-52.

18 Chacko JA, Zafar MB, McCallum SW, Terris MK. Vasectomy and prostate cancer characteristics of patients referred for prostate biopsy. J Urol 2002;168:1408-11. doi:10.1016/S0022-5347(05)64461-8.

19 Emard JF, Drouin G, Thouez JP, Ghadirian P. Vasectomy and prostate cancer in Québec, Canada. Health Place 2001;7:131-9. doi:10.1016/ S1353-8292(01)00005-3.

20 Hayes RB, Pottern LM, Greenberg R, et al. Vasectomy and prostate cancer in US blacks and whites. Am J Epidemiol 1993;137:263-9.

21 Mettlin C, Natarajan N, Huben R. Vasectomy and prostate cancer risk. Am J Epidemiol 1990;132:1056-61, discussion 1062-5.

22 Hsing AW, Wang RT, Gu FL, et al. Vasectomy and prostate cancer risk in China. Cancer Epidemiol Biomarkers Prev 1994;3:285-8.

23 Zhu K, Stanford JL, Daling JR, et al. Vasectomy and prostate cancer: a case-control study in a health maintenance organization. Am J Epidemiol 1996:144:717-22. doi:10.1093/oxfordjournals.aje.a008994.

24 John EM, Whittemore AS, Wu AH, et al. Vasectomy and prostate cancer: results from a multiethnic case-control study. J Natl Cancer Inst 1995;87:662-9. doi:10.1093/inci/87.9.662.

25 Stanford JL, Wicklund KG, McKnight B, Daling JR, Brawer MK. Vasectomy and risk of prostate cancer. Cancer Epidemiol Biomarkers Prev 1999:8:881-6.

26 Holt SK, Salinas CA, Stanford JL. Vasectomy and the risk of prostate cancer. J Urol 2008;180:2565-7, discussion 2567-8. doi:10.1016/j. juro.2008.08.042

27 Rosenberg L, Palmer JR, Zauber AG, Warshauer ME, Stolley PD, Shapiro S. Vasectomy and the risk of prostate cancer. Am J Epidemiol 1990;132:1051-5, discussion 1062-5.

28 Sidney S, Quesenberry CP Jr, , Sadler MC, Guess HA, Lydick EG, Cattolica EV. Vasectomy and the risk of prostate cancer in a cohort of multiphasic health-checkup examinees: second report. Cancer Causes Control 1991;2:113-6. doi:10.1007/BF00053130.

29 Honda GD, Bernstein L, Ross RK, Greenland S, Gerkins V, Henderson BE. Vasectomy, cigarette smoking, and age at first sexual intercourse as risk factors for prostate cancer in middle-aged men. Br J Cancer 1988:57:326-31. doi:10.1038/bjc.1988.74.

30 Siddiqui MM, Wilson KM, Epstein MM, et al. Vasectomy and risk of aggressive prostate cancer: a 24-year follow-up study. J Clin Oncol 2014;32:3033-8. doi:10.1200/JCO.2013.54.8446.

31 Gann PH, Hennekens CH, Ma J, Longcope C, Stampfer MJ. Prospective study of sex hormone levels and risk of prostate cancer. J Natl Cancer Inst 1996;88:1118-26. doi:10.1093/jnci/88.16.1118.

32 Reinberg A, Smolensky MH, Hallek M, Smith KD, Steinberger E. Annual variation in semen characteristics and plasma hormone levels in men undergoing vasectomy. Fertil Steril 1988;49:309-15. doi:10.1016/ S0015-0282(16)59721-0.

33 Glavind K, Lauritsen NR, Kløve-Mogensen M, Carl J. The effect of vasectomy on the production of plasma luteinizing hormone and follicle stimulating hormone in man. Int Urol Nephrol 1990;22:553-9. doi:10.1007/BF02549744.

34 Mo ZN, Huang X, Zhang SC, Yang JR. Early and late long-term effects of vasectomy on serum testosterone, dihydrotestosterone, luteinizing hormone and follicle-stimulating hormone levels. J Uro 1995:154:2065-9. doi:10.1016/S0022-5347(01)66696-5.
35 Skegg DC, Mathews JD, Guillebaud J, et al. Hormonal assessment before and after vasectomy. BrMed / 1976;1:621-2. doi:10.1136/ bmi.1.6010.621.

36 de la Torre B, Hedman M, Jensen F, Pedersen PH, Diczfalusy E. Lack of effect of vasectomy on peripheral gonadotrophin and steroid levels. Int J Androl 1983;6:125-34. doi:10.1111/j.1365-2605.1983.tb00331.x.

37 Leitzmann MF, Platz EA, Stampfer MJ, Willett WC, Giovannucci E. Ejaculation frequency and subsequent risk of prostate cancer. JAMA 2004:291:1578-86. doi:10.1001/jama.291.13.1578

38 Rosenblatt KA, Wicklund KG, Stanford JL. Sexual factors and the risk of prostate cancer. Am J Epidemiol 2001;153:1152-8. doi:10.1093/ aje/153.12.1152.

39 Ontario Ministry of Finance. Ontario Population Projections, 2013-2041. 2014

40 Brenner DR, Tammemägi MC, Bull SB, Pinnaduwaje D, Andrulis IL. Using cancer registry data: agreement in cause-of-death data between the Ontario Cancer Registry and a longitudinal study of breast cancer patients. Chronic Dis Can 2009;30:16-9.

41 Hall S, Schulze K, Groome P, Mackillop W, Holowaty E. Using cancer registry data for survival studies: the example of the Ontario Cance Registry. J Clin Epidemiol 2006;59:67-76. doi:10.1016/j. jclinepi.2005.05.001

42 Juurlink DN. Canadian institute for health information discharge abstract database: a validation study. Institute for Clinical Evaluative Sciences, 2006

43 Margel D, Urbach DR, Lipscombe LL, et al. Metformin use and all-cause and prostate cancer-specific mortality among men with diabetes. J Clin Oncol 2013;31:3069-75. doi:10.1200/ JCO.2012.46.7043.

44 Lega IC, Austin PC, Gruneir A, Goodwin PJ, Rochon PA, Lipscombe LL. Association between metformin therapy and mortality after breast cancer: a population-based study. Diabetes Care 2013;36:3018-26. doi:10.2337/dc12-2535.

45 Atzema CL, Grewal K, Lu H, Kapral MK, Kulkarni G, Austin PC. Outcomes among patients discharged from the emergency department with a diagnosis of peripheral vertigo. Ann Neurol 2016;79:32-41. doi:10.1002/ana.24521.

46 Nayan M, Macdonald EM, Juurlink DN, et al. Canadian Drug Safety and Effectiveness Research Network (CDSERN). Medication use and survival in diabetic patients with kidney cancer: A population-based cohort study. Pharmacol Res 2016;113(Pt A):468-74. doi:10.1016/j. phrs.2016.09.027

47 Austin PC, van Walraven C, Wodchis WP, Newman A, Anderson GM. Using the Johns Hopkins Aggregated Diagnosis Groups (ADGs) to predict mortality in a general adult population cohort in Ontario, Canada. Med Care 2011;49:932-9. doi:10.1097/ MLR.0b013e318215d5e2.

48 Austin PC, van Walraven C, Wodchis WP, Newman A, Anderson GM Using the Johns Hopkins Aggregated Diagnosis Groups (ADGs) to predict mortality in a general adult population cohort in Ontario, Canada. Med Care 2011;49:932-9. doi:10.1097/ MLR.0b013e318215d5e2.

49 Walsh TJ, Schembri M, Turek PJ, et al. Increased risk of high-grade prostate cancer among infertile men. Cancer 2010;116:2140-7.

50 McGregor SE, Hilsden RJ, Li FX, Bryant HE, Murray A. Low uptake of colorectal cancer screening $3 \mathrm{yr}$ after release of national recommendations for screening. Am J Gastroenterol 2007;102:172735. doi:10.1111/j.1572-0241.2007.01217x.

51 Liu L, Cozen W, Bernstein L, Ross RK, Deapen D. Changing relationship between socioeconomic status and prostate cancer incidence. J Natl Cancer Inst 2001;93:705-9. doi:10.1093/jnci/93.9.705.

52 Eisenberg ML, Henderson JT, Amory JK, Smith JF, Walsh TJ. Racial differences in vasectomy utilization in the United States: data from the national survey of family growth. Urology 2009;74:1020-4. doi:10.1016/j.urology.2009.06.042.

53 Hayes RB, Pottern LM, Strickler H, et al. Sexual behaviour, STDs and risks for prostate cancer. Br J Cancer 2000;82:718-25. doi:10.1054/ bjoc.1999.0986.

54 Nutt M, Reed Z, Köhler TS. Vasectomy and prostate cancer risk: a historical synopsis of undulating false causality. Res Rep Urol 2016;8:85-93. doi:10.2147/RRU.S71325.

55 Sharlip ID, Belker AM, Honig S, et al. American Urological Association. Vasectomy: AUA guideline. J Urol 2012;188(Suppl):2482-91. doi:10.1016/j.juro.2012.09.080

56 Bakalar N. A vasectomy may increase prostate cancer risk. New York Times 2014. http://well.blogs.nytimes. com/2014/07/17/a-vasectomy-may-increase-prostate-cancer-risk/.

57 American Urological Association. AUA Responds to Study Linking Vasectomy with Prostate Cancer. 2014. https://www.auanet.org/ press-media/vasectomy-with-prostate-cancer.cfm

58 Shih G, Turok DK, Parker WJ. Vasectomy: the other (better) form of sterilization. Contraception 2011;83:310-5. doi:10.1016/j. contraception.2010.08.019.

Supplementary information: tables S1-S4 